\title{
An Investigation of Success Factors in a High School Algebra Intervention Program
}

\author{
Sherri Kulpa \\ EducationPlus, United States \\ Sherrie Wisdom \\ Lindenwood University, United States
}

\begin{abstract}
This quantitative study allowed investigation of a high school Algebra intervention program through examination of potential relationships among teachers' beliefs about teaching and learning, teachers' instructional styles, students' academic self-concept in mathematics, and students' mathematics achievement. Existing research focused on individual components used in this study on the elementary level; thus, leaving a gap in understanding of how factors related to the success of high school students. Results may provide information to teachers and administrators regarding relationships among factors shown to impact student achievement in mathematics, and provide evaluation of an Algebra intervention program at the secondary level. The researcher utilized the National Council of Teachers of Mathematics Teaching and Learning Beliefs Questionnaire to identify beliefs about teaching and learning mathematics and the Reformed Teaching Observation Protocol (RTOP) to determine how closely instruction in Algebra classrooms aligned with constructivist practices. Students were given the Academic Self-Description Questionnaire II (ASDQII) as preand-post measures of academic self-concept in relation to mathematics; then, data were checked for relationships to achievement, measured by common semester final exams. Pearson Product Moment Correlation Coefficient analysis determined significant relationships existed between RTOP scores and the ASDQII prompts: I am hopeless when it comes to mathematics; work in mathematics is easy for me; and I get good marks in mathematics classes. Significant relationships were defined between Teaching Style and both Productive and Unproductive Teacher Beliefs, as well as between students' academic self-concept in mathematics and overall mastery of Algebra content, measured by scores on common semester finals.
\end{abstract}

Keywords: Algebra; Beliefs; Constructivist; High school; Intervention; Self-concept

\section{Introduction}

This quantitative study investigated implementation of an Algebra I intervention program at a suburban high school by examining teacher beliefs about teaching math; students' academic self-perceptions related to math; instructional practices in algebra classrooms; and the amount of time a student receives additional intervention support, as related to student achievement in Algebra I.

The research site was the high school in a district of 5000 students and served approximately 1800 in grades nine through 12. Despite the school's overall success, teachers and administrators identified a group of students who were behind their peers in the level of mathematics courses taken or in relation to grades in previous math classes and scores on standardized tests. The intervention program was designed to support students who did not take Algebra I prior to entering high school, which placed them at risk for completing fewer math courses than their peers (Cirino et al., 2018; McEachin et al., 2017). The majority of students at the school took Algebra I in 8th grade. Thus, students not enrolled in Algebra I prior to entering high school were behind their peers in 
coursework, and deemed 'at risk' in terms of math achievement.

\section{Statement of the Problem}

Although research generally supported Algebra for eighth graders, some students found early Algebra challenging (Clotfelter et al., 2015; National Council of Teachers of Mathematics [NCTM], 2014; Stein et al., 2011). National Assessment of Educational Progress (NAEP) reported a drop in mathematics scores in 2015 (as cited in Mullis et al., 2016), with high school seniors scoring lower than seniors who took the test in 2013 (Nation's Report Card, 2016). Additionally, professional organizations, such as the National Council of Teachers of Mathematics (NCTM, n.d.), in an effort to increase achievement, revised standards to outlining not only content, but process standards, including, "problem solving, reasoning and proof, communication, connections, and representation" (para. 5).

Despite these efforts, gains in mathematics scores on international and national assessments failed to rise significantly (Office of Economic and Cooperative Development [OECD], 2018b; Mullis et.al., 2016). Likewise, despite recognition as a Top Ten school in the state and efforts to improve student support, research-site scores on Algebra I EOCs were not improving at the expected rate (Missouri Department of Elementary and Secondary Education [MODESE], n.d.).

\section{Rationale}

Evaluation of efforts to support mathematics at the research site was needed. Previous to the study, to improve achievement for students struggling to meet grade-level expectations, the research site responded by restructuring student access to instructional supports. The high school reviewed math data, and determined the greatest need related to support for mathematics achievement was though a focus on Algebra I, considered a gate-keeper class (Burdman, 2018; Cortez et al., 2013; Fisher \& Frey, 2013; Loveless, 2013). The site added an Algebra I support teacher with a background in special education and structured this teacher's schedule to include time for analysis of achievement data and to meet with students who showed signs of struggle, as identified by classroom data, teachers, student self-report.

At the time of this study, the support role had been in place for two years and standardized test data showed little change in overall achievement in Algebra I state assessments. The researcher sought to more-closely examine the program by studying relationships among student self-concept, teacher beliefs about teaching math, instructional styles, and overall achievement in Algebra I. Identified relationships could then inform potential next steps regarding the structure of the Algebra I intervention program.

\section{Hypotheses}

\section{Hypothesis 1}

There is a relationship between students' academic self-concept, as measured by the ASDQII, and teachers' beliefs about the teaching of algebra as measured by the Teacher Belief Survey.

\section{Hypothesis 2}

There is a relationship between students' academic self-concept in math, as measured by the ASDQII and the instructional practices in the classroom as measured by the Reformed Teaching Observation Protocol (RTOP). 


\section{Hypothesis 3}

There is a relationship between Algebra I mastery, as measured by student results on Algebra I semester comprehensive finals and teachers' beliefs about the teaching of algebra, as measured by the Teacher Belief Survey.

\section{Hypothesis 4}

There is a relationship between Algebra I mastery, as measured by student results on Algebra I comprehensive semester finals and the instruction used in the Algebra I classrooms, as measured by the RTOP.

\section{Hypothesis 5}

There is a relationship between teacher beliefs, as measured by the Teacher Belief Survey and instructional practices in the Algebra I classroom, as measured by the RTOP.

\section{Hypothesis 6}

There is a relationship between student academic selfconcepts, as measured by the ASCDII and Algebra I mastery, as measured by scores on Algebra I comprehensive semester finals.

\section{Methods}

\section{Population and Sample}

Following the two-year Algebra-I intervention, which yielded limited improvement in student assessment results, the researcher launched this one-year study on potential relationships between student self-concept, teacher beliefs, instructional styles, and overall achievement. The researcher met with teachers to explain the purpose of the study and secure all Algebra I teachers as voluntary participants in the study. To recruit student participants, the researcher created an informational video, which was shared during Algebra I class time, and teachers handed out assent and consent forms to students. In addition, the researcher attended a parent open house to answer any questions and encourage participation in the study. All students enrolled in Algebra I at the high school were eligible to participate, and, based on returning both student assent and parental consent forms, the resulting sample included 71 students.

The research population for this study included four teachers and 203 students. The four teachers selected were those assigned to Algebra I at the research site. The students were selected through random sampling.

\section{Teacher Participants}

The math department consisted of 15 teachers. Of the four Algebra I teachers, one was in the second year of teaching; one had nine years of experience; the third had been teaching for 10 years, and the fourth brought 23 years of experience to the classroom. None of the four teachers had taught other content areas outside of math, nor had any taught at a level different than high school, or grades 9 to 12 . Two of the four had experience in another district and two achieved National Board Certification (NBC) in Adolescence and Young Adulthood in Mathematics. Of the two teachers with NBC, one was recognized as a Teacher of the Year at a high school in a neighboring district.

Teachers at the research site had the opportunity to regularly participate in professional development at the district level, department level, and independently. The district provided professional learning during two full-day sessions for all teachers in the district on the topic of equity, a district-wide focus at the time. The district also led a mathematics curriculum cycle 
review and one teacher in the study served as a high school representative on the district committee.

The research site was in the beginning stages of learning to create common assessments and utilize student responses to inform instruction and respond to students' needs. Teachers participated in this professional development during after-school faculty meetings and monthly early-release days. Due to the nature of the data-team work, teachers typically worked either as a department or according to the courses taught, which meant the Algebra I teachers met multiple times throughout the year to develop common assessments and discuss data generated by the assessments.

At the building level, administrators of the research site frequented department meetings to support application of new learning around common assessments and data teams, and expected each course to develop four common assessments during the time span of the study, which the Algebra I teachers accomplished.

\section{Student Participants}

The student research population consisted of 203 high school students enrolled in an Algebra I course at the research site. Students' enrollment in Algebra I was based on recommendation by an eighth-grade teacher or counselor, parent request, lack of Algebra I credit due to transfer from a private school or other institution that did not offer Algebra I to eighth-grade students, or repeating the course due to earning a failing grade.

As shown in Table 1, students ranged in age from 14 to 17 , with the majority of participants reported as
Caucasian; 75\%. Table 1 indicates age, race, gender, MAP Mathematics Proficiency, and Transfer rate. Most scored proficient or advanced on the state standardized assessment taken when students were in eighth grade. Due to transfers from private or parochial schools, some students did not have an eighth-grade standardized test score, as they were not required to take the assessment.

\section{Table 1}

Study Sample Demographic Characteristics

\begin{tabular}{lrr}
\hline Characteristic & Number $\begin{array}{l}\text { Percentage of } \\
\text { Sample }\end{array}$ \\
\hline Age & 49 & 72 \\
14 & 14 & 21 \\
15 & 3 & 4 \\
16 & 2 & 3 \\
17 & & \\
\hline Race & 7 & 10 \\
\hline African American & 4 & 6 \\
Asian & 51 & 75 \\
Caucasian & 3 & 4 \\
Hispanic & 3 & 4 \\
Multi-racial & & \\
\hline Gender & 37 & 54 \\
\hline Female & 31 & 46 \\
Male & 8 & 10 \\
\hline 8th Grade Missouri Assessment in Mathematics \\
Proficiency Score & & 10 \\
\hline Below Basic & 6 & 56 \\
Basic & 7 & 7 \\
Proficient & 38 & 17 \\
Advanced & 5 & \\
No Score Available & 12 & \\
\hline Transfer & & \\
\hline From Public School & 4 & \\
From Private School & 8 & \\
\hline & & \\
\hline
\end{tabular}




\section{Instrumentation and Data Collection}

\section{Student Factors}

The Academic Self-Description Questionnaire II (ASDQII), designed to measure academic self-concept of students in seventh through 12th grades, was used as both a pre- and post-test. According to researchers, the ASDQII was a valid and reliable method for understanding students' academic self-concept (Marsh, 1990; Pena et al., 2015). A quantitative survey, the ASDQII utilized an eight-point Likert scale, which asked students to reflect on how true or false each statement was in relation to students' feelings about mathematics. Statements connected to each point on the scale included: Definitely False, Mostly False, False, More False Than True, More True Than False, Mostly True, True, and Definitely True. Because research confirmed that academic selfconcept was domain specific (Liem et al., 2015; Marsh, 1990; Niepel et al., 2014), the researcher modified the ASDQII survey to include only questions related to mathematics.

Seventy-one students completed the ASDQII as a pretest during a single homeroom period at the beginning of the study. When administered as a post-test in the spring of the same school year, only 23 students participated, due in part to one teacher who failed to provide the assessment to students. Because all but one statement on the survey was written in the affirmative, the negative statement was reverse scored for purposes of analysis. Additionally, student scores on common semester finals were collected for the population sample of 71 students. Created collaboratively by the Algebra I teachers, the semester finals were cumulative, covering one year of Algebra I content.

\section{Teacher Factors}

Teachers' beliefs about teaching and learning were collected using the NCTM's (2014) Teaching and Learning Beliefs Survey, which consisted of 12 questions regarding aspects of both teaching and learning and aligned with NCTM productive and unproductive thinking. Respondents selected from a four-point Likert scale to indicate their level of disagreement or agreement with each statement. The mean score for both productive and unproductive beliefs was computed, with high scores indicating strong alignment to productive or unproductive beliefs and low scores indicating little or no alignment.

In order to gather data on teaching styles implemented by the teachers in the study, the researcher observed each teacher three times during the study. Using the RTOP, the researcher rated three broad categories: lesson planning and implementation, the content of the lesson, and the classroom climate and culture on a five-point scale, to indicate how accurately each statement reflected the observed instruction.

The NCTM standards included "problem solving, reasoning and proof, communication, connections, [and] representations" (NCTM, n.d., para. 5), which aligned with the fundamental practices outlined in the constructivist approach to mathematics instruction measured by the Reformed Teaching Observation Protocol (Piburn \& Sawada, n.d.). Reformed teaching, or teaching constructivist in nature, was identified as instruction that called upon students' prior knowledge, allowed for multiple pathways toward solutions, and helped students make connections both between mathematical concepts and other content areas (Boston et al., 2015). 
Designed to determine how well instruction aligned with reformed teaching practice (defined as constructivism for this study) in mathematics and science, the RTOP provided a quantitative description for three broad categories: lesson design and implementation, content, and classroom culture (Classroom Observation Project, 2018; Piburn \& Sawada, n.d.; Sawada et al., 2002). Sawada et al. (2002) confirmed the reliability of the RTOP by computing Chronbach's alpha for both subsets of the observation tool and the assessment as a whole, with the resulting alpha of 0.97 , indicating strong internal reliability.

Twenty-five items were scored using a rubric scale of zero to four, with zero indicating the item was not observed and four indicating the item was "very descriptive of the lesson" (Boston et al., 2015, p. 156); total scores were used to indicate the degree of constructivist approaches used by the instructor, as outlined in Table 2 (Classroom Observation Project, 2018). Teachers were observed three times, and a mean score for each teacher was calculated.

\section{Table 2}

Interpreting Reformed Teaching Observation Protocol Scores

\begin{tabular}{cl}
\hline Score & Type of \\
& Instruction \\
$0-29$ & Traditional \\
& Lecture \\
$30-49$ & Active Lecture \\
$50+$ & Constructivist \\
\hline
\end{tabular}

\section{Student Assessment Scores}

There was no state-required Algebra End-of-Course exam for these students during this study. The researcher utilized data from common finals given both first and second semester in the Algebra I course.

\section{Limitations}

Because four teachers were assigned to Algebra I during the study, one limitation was the small population size accessible to the researcher. While the results of the study may not be easily generalized to all Algebra I teachers in all settings, according to Fraenkel et al. (2018), "a population can be any size" (p. 92) and the population of four teachers can be appropriately applied to all Algebra I teachers at the study site during the study school year. Additionally, the population of teachers in the study was largely, if not solely, responsible for the mathematics instruction of the student sample throughout the school year, meeting with the students every day for a minimum class period of 55 minutes to a maximum of 90 minutes, thereby strengthening the results of the relationship between factors studied.

Another limitation to the study was mortality, which occurred in the student sample over the course of the school year. Initially, the sample included any student for whom both the student assent and parental consent forms were completed and returned, which resulted in 71 out of 203 students in the initial sample. The final phase of the study asked students to complete the ASCDII a second time as a post-test, and 23 of the 71 students participated. Completion of the post-test ASCDII took place during students' academic homeroom periods. The pre-test required that students convene in the cafeteria, where they were given the details of the survey and took the assessment in a large-group setting. 
Because the second ASCDII was given during the final months of school, when standardized assessments and finals were a focus for both teachers and students, the researcher was asked to make the assessment available electronically, to avoid pulling students out of academic support during homeroom. This change in the way the survey was provided to students may have impacted the number of students taking the assessment. Because the delivery of the survey changed, location threat may also be a reason for the decrease in the number of students taking the post survey. The novelty of the first data collection occurring in a large group setting could result in more positive scores on the first assessment, as compared to the second assessment, as well as account for the fewer number of students taking the post-survey.

Although the RTOP was shown to be reliable (Sawada et al., 2002) and the researcher completed the suggested online calibration activities, using only one person to document classroom observations may pose some threat to validity (Piburn \& Sawada, n.d.).

Student-related limitations included the process for identifying subjects for the study and the design of the student survey. Because both parent consent and student assent forms were required for each subject, due to age, teachers were asked to explain the study and hand out consent forms to parents who attended open house. As a result, all student subjects in the study had parents who attended open house, which could be an influential factor in student achievement, but was not part of this study.

The Hawthorne Effect could impact the responses of the teachers on the Teacher Perception Survey, as well as their behaviors in the classrooms while videotaped and/or observed, because they knew they were part of a study and the survey tool provided some information regarding what was studied (American Psychological Association, 2020).

\section{Results}

\section{Hypotheses Results}

\section{Hypothesis 1}

A relationship between students' academic selfconcept as measured by the ASDQII, and teachers' beliefs about the teaching of Algebra I as measured by the Teacher Belief Survey was not supported.

Results of the PPMCC revealed no significant relationship between students' pre or post scores on the survey of academic self-concept in mathematics and teachers' beliefs regarding the best way to teach math, both productive or unproductive, as classified by the NCTM Teacher Belief Survey. Statistical results for the ASDQII Pre-Score to Teacher Belief Unproductive were $\mathrm{n}=71, \alpha=.01, r$-critical $=.303$, and $r=.110$, and $\mathrm{n}=71, \alpha=.05, r$-critical $=.232$, and $r=.110$. The results for the ASDQII Post-Score to Teacher Belief Productive were $\mathrm{n}=23, \alpha=.01, r$ critical $=.505$, and $r=.064$ and $\mathrm{n}=23, \alpha=.05, r$ critical $=.396$, and $r=.064$.

Within this data set, statistically significant relationships between pre- and post-scores on the ASDQII were evident. With a correlation of 0.739 at a significance level of 0.01 (two-tailed), student survey results showed a positive relationship between the preand post-surveys; that is, high scores on the ASDQII given as a pre-survey correlated with high scores on the same survey given as a post-survey. Statistical results for the ASDQII pre-survey to the ASDQII postsurvey were $\mathrm{n}=23, \alpha=.01, r$-critical $=.505$, and $r=$ 
.739 and $\mathrm{n}=23, \alpha=.05, r$-critical $=.396$, and $r=.739$.

Therefore, the null hypothesis was not rejected for this comparison and the hypothesis was not supported.

Similarly, a correlation of 0.558 at a significance level of 0.01 (two-tailed) between productive and unproductive beliefs about teaching mathematics indicated a statistically significant positive relationship. In other words, when scores on unproductive beliefs about teaching math increased, there was also an increase in scores on productive beliefs about teaching math. Likewise, if one variable decreased, the other followed suit. Statistical results for the Productive Belief Survey to the Unproductive Belief Survey were $\mathrm{n}=71, \alpha=.01, r$-critical $=.303$, and $r=.558$ and $\mathrm{n}=71, \alpha=.05, r$-critical $=.303$, and $r=.558$. Therefore, the null hypothesis was not rejected for this comparison and the hypothesis was not supported.

A small inverse relationship was revealed between unproductive teacher beliefs and students' selfconcept in mathematics. The results for the ASDQII Post-Score to Teacher Belief Unproductive were $\mathrm{n}=$ 23, $\alpha=.01, r$-critical $=.505$, and $r=-.197$ and $\mathrm{n}=23$, $\alpha=.05, r$-critical $=.396$, and $r=-.197$. While the $r$ value was not high enough to cause the researcher to reject the null hypothesis, descriptively the relationship suggests that as teachers' levels of agreement with unproductive math statements on the NCTM survey increased, students became less confident in their ability to do well in mathematics.

\section{Hypothesis 2}

A relationship between students' academic selfconcept in mathematics as measured by the ASDQII and the instructional practices in the classroom as measured by the RTOP was not supported.

Pearson Product Correlation Coefficients are shown in Table 3. Using boundaries suggested by Laerd (2018), the correlation between students' self-perception about mathematics and the style of teaching used by their instructors was small at 0.269 , when looking at both the ASDQII pre survey and ASDQII post survey, which indicated no relationship between these factors. Statistical results for the ASDQII Pre-Score to Teaching Style were $\mathrm{n}=71, \alpha=.01, r$-critical $=.303$, and $r=.269$. The results for the ASDQII Post-Score to Teaching Style were $\mathrm{n}=23, \alpha=.01, r$-critical $=.505$, and $r=.269$ and $\mathrm{n}=23, \alpha=.05, r$-critical $=.396$, and $r=.269$. As a result, the researcher failed to reject the null and did not support the hypothesis.

\section{Table 3}

Students' Self Perception in Mathematics and Instructor's Teaching Style

\begin{tabular}{cccc}
\hline & $\begin{array}{c}\text { ASDQII } \\
\text { Pre } \\
\text { Scale } \\
\text { Average }\end{array}$ & $\begin{array}{c}\text { ASDQII } \\
\text { Post } \\
\text { Scale } \\
\text { Summary }\end{array}$ & $\begin{array}{c}\text { Teaching } \\
\text { Style } \\
\text { (RTOP) }\end{array}$ \\
\hline ASDQII Pre & 1.0 & $1.000^{* *}$ & 0.269 \\
$\begin{array}{c}\text { Scale Average } \\
\text { ASDQII Post } \\
\text { Scale }\end{array}$ & $1.000^{* *}$ & 1.0 & 0.269 \\
$\begin{array}{c}\text { Summary } \\
\text { Teaching }\end{array}$ & & & \\
Style (RTOP) & 0.269 & 0.269 & 1.0 \\
** Correlation is significant at the 0.01 level (2-tailed). \\
$\mathrm{n}=71$, all correlations.
\end{tabular}

The researcher looked at the relationship between specific questions within the ASDQII and teachers' teaching styles, which revealed some statistically significant results as shown in Table 4, but the results did not impact the overall null hypotheses. 
Table 4

Students' Self Perception in Mathematics and Specific RTOP Scores

RTOP Score

RTOP Score

ASDQII Pre Q1: I am hopeless when it comes to mathematics

$-0.340 * *$

$\mathrm{N}=71$

ASDQII Pre Q5: Work in

mathematics is easy for me

$0.257^{*}$

$\mathrm{N}=71$

ASDQII Pre Q6: I get good marks in mathematics classes

$0.278^{*}$

$\mathrm{N}=71$

* Correlation is significant at the 0.05 level (2-tailed);

** Correlation is significant at the 0.01 level (2-tailed). $\mathrm{n}=23$, all correlations.

The correlation between students' responses on specific questions within the ASDQII and their teachers' scores on the RTOP revealed three statistically significant results from the pre-survey and no statistically significant results on the post survey. Statistical results for the ASDQII Pre-ScoreQ1 to RTOP $\mathrm{n}=23, \alpha=.01, r$-critical $=.505$, and $r=-.340$, and $\mathrm{n}=23, \alpha=.05, r$-critical $=.396$, and $r=-.340$. Results for the ASDQII Pre-ScoreQ5 to RTOP $\mathrm{n}=23$, $\alpha=.01, r$-critical $=.505$, and $r=.257$, and $\mathrm{n}=23, \alpha=$ .05 , r-critical $=.396$, and $r=.257$. Results for the ASDQII Pre-ScoreQ6 to RTOP $\mathrm{n}=23, \alpha=.01, r$ critical $=.505$, and $r=.278$, and $\mathrm{n}=23, \alpha=.05, r$ critical $=.396$, and $r=.278$.

Question one revealed an inverse correlation, -0.340 , which indicated as an individual teacher's level of constructivism increased, students in that class had decreasing levels of hopelessness related to their abilities to do well in math. The inverse was also true; as a teacher's level of constructivism decreased, students in that classroom had increasing feelings of hopelessness related to doing well in math. Questions five (0.257) and six (0.278) on the ASDQII pre-survey were positively correlated to their teachers' level of constructivism as assessed by the RTOP, indicating that as a teacher's RTOP score increased, students' perceptions of the ease of work in math class and their perceived ability to achieve high grades in math also increased.

No statistically significant results existed between student academic self-perception scores on the post survey and their teachers' score on the RTOP, which is likely due to the change in sample size from 71 students to 23. As discussed in Chapter Three, the mortality rate in the study was the result of one teacher failing to provide the post survey to students.

\section{Hypothesis 3}

A relationship between Algebra I mastery as measured by student results on Algebra I semester comprehensive finals and teachers' beliefs about the teaching of algebra, as measured by the Teacher Belief Survey was not supported.

Using a PPMCC analysis, the researcher determined that there was no statistically significant relationship between student scores on semester finals and productive teacher beliefs, as defined by the NCTM Teacher Belief survey. The researcher analyzed each question on the NCTM survey in relation to students' scores on semester finals, and found that while none of the teacher perceptions were significantly related to student assessment scores, three questions did have a small, observable association when using Laerd's (2018) boundaries for analysis. 
For both first and second semester course finals, questions five, nine, and eleven showed a small positive, observable association with student scores. These questions specifically called out the importance of students as active participants in learning mathematics. As teachers' scores on these questions more strongly indicated agreement with the statements, students' scores on semester finals would also increase. Likewise, as teachers' scores on questions five, nine, and eleven decreased, indicating less agreement with the statements, students' scores on semester finals would likely decrease. A similar approach was applied to unproductive beliefs.

As was the case with semester finals and productive beliefs, using a PPMCC revealed no statistically significant relationship between students' scores on semester finals and unproductive teaching beliefs. as defined by the NCTM Teacher Belief Survey. As a result, the researcher failed to reject the null hypothesis and did not support the hypothesis.

One question, categorized as unproductive, revealed a small, nonsignificant, relationship. Question number 10 on the Teacher Belief Survey states, "The role of the student is to memorize information that is presented and then use it to solve routine problems on homework, quizzes and tests" (NCTM, 2014, p. 11). The relationships between first and second semester finals and question 10 were 0.129 and 0.127 , respectively. Using Laerd's (2018) boundaries, the results indicated a positive, observable relationship. In other words, as teachers' levels of agreement with the statement increased, students' scores on semester finals also increased and as teachers' levels of agreement with question 10 decreased, students' scores on semester finals would also decrease. This interested the researcher as the statement is defined as unproductive, yet data implied that higher levels of agreement with the statement yielded improved scores on teacher-created assessments.

Because no statistically significant relationships were shown between scores on semester finals and teacher productive and unproductive beliefs about teaching, the researcher failed to reject the null and did not support the hypothesis.

\section{Hypothesis 4}

A relationship between Algebra I mastery, as measured by student results on Algebra I comprehensive semester finals and the instruction used in the Algebra I classrooms as measured by the RTOP was not supported.

Pearson Product Moment Correlation Coefficients are displayed in Table 5.

To assess the relationship between student scores on semester finals and the teacher observation score, as measured by the RTOP, the researcher used a PPMCC. First and second semester final scores were each examined individually along with an average of the semester scores. All student scores were presented as a percentage. The $\mathrm{p}$-value was significant at the 0.01 level ( 2 tailed) with a critical value (r) of 0.354 . As shown in Table 5, there is no significant correlation between students' scores on semester finals and the degree of constructivist teaching employed by teachers in the Algebra I classroom. This was true for both first and second semester finals individually and the average of the two scores, therefore, the researcher failed to reject the null and did not support the hypothesis. 
Table 5

Relationship Between Semester Final Scores and RTOP Scores

\begin{tabular}{|c|c|c|c|c|c|}
\hline & & $\begin{array}{l}\text { 1st Semester } \\
\text { Final } \\
\text { Percentage }\end{array}$ & $\begin{array}{l}\text { 2nd Semester } \\
\text { Final } \\
\text { Percentage }\end{array}$ & $\begin{array}{l}\text { Average of } \\
\text { Semester Final } \\
\text { Scores }\end{array}$ & $\begin{array}{l}\text { RTOP } \\
\text { Observation } \\
\text { Score }\end{array}$ \\
\hline \multirow[t]{2}{*}{$\begin{array}{l}\text { 1st Semester } \\
\text { Final } \\
\text { Percentage }\end{array}$} & $\begin{array}{l}\text { Pearson } \\
\text { Correlation }\end{array}$ & 1.0 & $0.884 * *$ & $0.954 * *$ & 0.135 \\
\hline & $\mathrm{n}$ & 69 & 69 & 69 & 69 \\
\hline \multirow{2}{*}{$\begin{array}{l}\text { 2nd Semester } \\
\text { Final } \\
\text { Percentage }\end{array}$} & $\begin{array}{l}\text { Pearson } \\
\text { Correlation }\end{array}$ & $0.884 * *$ & 1.0 & $0.951 * *$ & 0.211 \\
\hline & $\mathrm{n}$ & 69 & 69 & 69 & 69 \\
\hline \multirow{2}{*}{$\begin{array}{l}\text { Average of } \\
\text { Semester Final } \\
\text { Scores }\end{array}$} & $\begin{array}{l}\text { Pearson } \\
\text { Correlation }\end{array}$ & $0.954 * *$ & $0.951 * *$ & 1.0 & 0.169 \\
\hline & $\mathrm{n}$ & 69 & 69 & 69 & 69 \\
\hline \multirow{2}{*}{$\begin{array}{l}\text { RTOP } \\
\text { Observation } \\
\text { Score }\end{array}$} & $\begin{array}{l}\text { Pearson } \\
\text { Correlation }\end{array}$ & 0.135 & 0.211 & 0.169 & 1.0 \\
\hline & $\mathrm{n}$ & 69 & 69 & 69 & 71 \\
\hline
\end{tabular}

**Correlation is significant at the 0.01 level (2-tailed).

Using an alpha of 0.01 and a critical value of 0.354 , the r-scores indicated only a small, observable, yet nonsignificant, direct relationship between scores on semester finals. As a result, the researcher failed to reject the null hypothesis and did not support the hypothesis. Additionally, data from second semester finals showed a higher correlation to the instructional style of the teacher than did scores on first semester finals; however, the correlation was not statistically significant.

\section{Hypothesis 5}

A relationship between teacher beliefs as measured by the Teacher Belief Survey and degree of constructivism evident in instructional practices in the
Algebra I classroom as measured by the RTOP was not supported.

The researcher used scores from the NCTM's Teaching Beliefs Survey and the RTOP score gleaned from classroom observations to examine the relationship between teacher beliefs about teaching mathematics and the style of instruction used in the classroom. Data from the Teaching Beliefs Survey were separated into productive and unproductive beliefs for analysis. Because none of the correlations fell into the critical area, the researcher failed to reject the null and did not support the hypothesis. See Table 6 for results for unproductive beliefs and styles. See Table 7 for results for productive beliefs and styles. 


\section{Table 6}

Unproductive Teacher Beliefs and Teaching Style

\begin{tabular}{|c|c|c|c|c|c|c|c|c|}
\hline & 1 & 2 & 3 & 4 & 5 & 6 & 7 & 8 \\
\hline 1 & 1.0 & -0.182 & $a$ & -0.190 & -0.190 & -0.172 & -0.058 & $a$ \\
\hline 2 & -0.182 & 1.0 & $a$ & $0.888 * *$ & $0.888 * *$ & $0.924 * *$ & $0.665^{* *}$ & $a$ \\
\hline 3 & $a$ & $a$ & 1.0 & $a$ & $a$ & $a$ & $a$ & $a$ \\
\hline 4 & -0.190 & $0.888 * *$ & $a$ & 1.0 & $1.000 * *$ & $0.711 * *$ & $0.275^{*}$ & $a$ \\
\hline 5 & -0.190 & $0.888 * *$ & $a$ & $1.000 * *$ & 1.0 & 0.711 & $0.275^{*}$ & $a$ \\
\hline 6 & -0.172 & $0.924 * *$ & $a$ & $0.711 * *$ & 0.711 & 1.0 & $0.690 * *$ & $a$ \\
\hline 7 & -0.058 & $0.665 * *$ & $a$ & $0.275^{*}$ & $0.275^{*}$ & $0.690 * *$ & 1.0 & $a$ \\
\hline 8 & $a$ & $a$ & $a$ & $a$ & $a$ & $a$ & $a$ & 1.0 \\
\hline
\end{tabular}

Note. ${ }^{* *}$ Correlation is significant at the 0.01 level (2-tailed); *correlation is significant at the 0.05 level (2-tailed); $a=$ cannot be computed because at least one variable is constant; $n=71$.

Table Legend: 1. RTOP Score; 2. Teacher Belief Scale Summary; 3. Teacher Belief Survey Q1: Mathematics learning should focus on practicing procedures and memorizing basic number combinations.; 4. Teacher Belief Survey Q2: The role of the teacher is to tell students exactly what definitions, formulas, and rules they should know and demonstrate how to use this information to solve mathematics problems.; 5 . Teacher Belief Survey Q6: An effective teacher makes the mathematics easy for students by guiding them step by step through problem solving to ensure that they are not frustrated or confused.; 6. Teacher Belief Survey Q7: Students can learn to apply mathematics only after they have mastered the basic skills; 7 . Teacher Belief Survey Q10: The role of the student is to memorize information that is presented and then use it to solve routine problems on homework, quizzes and tests.; 8. Teacher Belief Survey Q12: Students need only to learn and use the same standard computational algorithms and the same prescribed methods to solve algebraic problems.

\section{Table 7}

Productive Teaching Beliefs and Teaching Style

\begin{tabular}{ccccccccc}
\hline & 1 & 2 & 3 & 4 & 5 & 6 & 7 & 8 \\
\hline 1 & 1.0 & -0.026 & -0.172 & $a$ & -0.058 & -0.089 & 0.145 & 0.145 \\
2 & -0.026 & 1.0 & $.484 * *$ & $a$ & $0.949 * *$ & $0.795^{* *}$ & $0.591 * *$ & $0.591 * *$ \\
3 & -0.172 & $0.484 * *$ & 1.0 & $a$ & $0.690^{* *}$ & $0.466^{* *}$ & $-.393 * *$ & $-0.393 * *$ \\
4 & $a$ & $a$ & $a$ & 1.0 & $a$ & $a$ & $a$ & $a$ \\
5 & -0.058 & $0.949 * *$ & $.690^{* *}$ & $a$ & 1.0 & $0.675^{* *}$ & $0.393 * *$ & $0.393^{* *}$ \\
6 & -0.089 & $0.795^{* *}$ & $.466^{* *}$ & $a$ & $0.675^{* *}$ & 1.0 & $0.266^{*}$ & $0.266^{*}$ \\
7 & 0.145 & $0.591 * *$ & $-.393 * *$ & $a$ & $0.393 * *$ & $0.266^{*}$ & 1.0 & $1.000^{* *}$ \\
8 & 0.145 & $0.591 * *$ & $-.393 * *$ & $a$ & $0.393^{* *}$ & $0.266^{*}$ & $1.000^{* *}$ & 1.0 \\
\hline
\end{tabular}

**Correlation significant at the 0.01 level (2-tailed); ${ }^{*}$ Correlation significant at the 0.05 level (2-tailed); $a=$ cannot be computed because at least one of the variables is constant; $n=71$. 
Table Legend. 1. RTOP Score; 2. Teacher Belief Scale Summary; 3. Teacher Belief Survey Q3: All students need to have a range of strategies and approaches from which to choose in solving problems, including, but not limited to, general methods, standard algorithms, and procedures; 4 .

Teacher Belief Survey Q4: The role of the teacher is to engage students in tasks that promote reasoning and problem solving and facilitate discourse that moves students toward shared understanding of mathematics; 5. Teacher Belief Survey Q5: Mathematics learning should focus on developing understanding of concepts and procedures through problem solving, reasoning and discourse.; 6. Teacher Belief Survey Q8: Students can learn mathematics through exploring and solving contextual and mathematical problems.; 7. Teacher Belief Survey Q9: An effective teacher provides students with appropriate challenge, encourages perseverance in solving problems, and supports productive struggle in learning mathematics.; 8 . Teacher Belief Survey Q11: The role of the student is to be actively involved in making sense of mathematics tasks by using varied strategies and representations, justifying solutions, making connections to prior knowledge or familiar contexts and experiences, and considering the reasoning of others.

\section{Hypothesis 6}

A relationship between student academic self-concept, as measured by the ASDQII and Algebra I mastery, as measured by scores on Algebra I comprehensive semester finals was supported.

Pearson Product Correlation Coefficients are displayed in Table 8. Student self-concept in mathematics was measured using a modified version of the ASDQII, which included only questions related to math. The survey was given both at the beginning and the end of the study, although one teacher in the study did not give the survey to students, which resulted in a smaller sample size for the post-survey results. Results from both the pre- and post-survey were examined for a possible relationship with student scores on both first and second semester finals using a PPMCC.

\section{Table 8}

Student Self-Concept and Scores on Semester Finals

$\begin{array}{ccc}\text { 1st } & \text { 2nd } & \text { Avg. of } \\ \text { Semester } & \text { Semester } & \text { Semester } \\ \text { Final \% } & \text { Final \% } & \text { Finals }\end{array}$

\begin{tabular}{llll}
\hline $\begin{array}{c}\text { ASDQII Pre-Survey } \\
\mathrm{n}=71\end{array}$ & $0.447 * *$ & $0.449 * *$ & $0.445^{* *}$ \\
$\begin{array}{l}\text { ASDQII Post- } \\
\text { Survey n=23 }\end{array}$ & $0.428^{*}$ & $0.461^{*}$ & $0.452^{*}$ \\
$\begin{array}{l}\text { Difference Between } \\
\text { ASDQII Pre and } \\
\text { Post }\end{array}$ & -0.033 & -0.054 & -0.044 \\
* & & \\
Correlation significant at the 0.01 level (2-tailed); & \\
Correlation significant at the 0.05 level (2-tailed). &
\end{tabular}

Direct correlations between student self-concept in mathematics pre-survey and scores on both first and second semester finals were significant at the .01 level which indicated as students' self-concept in math increased, scores on Algebra finals for both semesters also increased (Table 6). Statistics results for ASDQII Pre to Scores on Semester Finals were $\mathrm{n}=71, \alpha=.01$, $r$-critical $=.303$, and $r=.445$, and $\mathrm{n}=71, \alpha=.05, r$ critical $=.232$, and $r=.445$. Results for ASDQII Post to Scores on Semester Finals were $\mathrm{n}=23, \alpha=.01, r$ critical $=.505$, and $r=.445$, and $\mathrm{n}=23, \alpha=.05, r$ critical $=.396$, and $r=.452$. The inverse was also true, meaning that as students' academic self-concept 
decreased, scores on Algebra I semester finals also decreased.

Post-survey results were significant at the 0.05 level and again showed a direct positive relationship between student self-concept in math and scores on Algebra I finals, meaning that as students' academic self-concept in math increased, scores on semester finals also increased.

Laerd's (2018) boundaries indicated a medium, positive relationship between students' academic selfconcept in mathematics and their grades on semester finals for both the pre- and post-survey. As shown by the data, when students' self-perception ratings regarding their abilities to do well in math class increased, their scores on Algebra I finals also increased. The more time students spent in Algebra I classrooms, the strength of the relationship increased, as shown by increased correlation strength of the post survey and second semester finals. However, the difference between the pre- and post-ASDQII surveys was not statistically significant.

As a result of the positive, medium relationship between the pre- and post-survey results and scores on semester finals, the researcher rejected the null hypothesis and supported the hypothesis. There is a relationship between students' self-perception in mathematics and achievement, as measured by Algebra I semester finals.

\section{Discussion}

\section{Systemic Factors}

Decisions regarding when students take Algebra, how students are grouped for Algebra, and the type of curriculum provided to Algebra teachers are systemic factors that should be addressed to improve achievement for all. When deciding between either eighth or ninth-grade enrollment in Algebra, research does not provide clear guidance. However, because Algebra is a gate-keeper course, and because research has shown that students who are not placed in Algebra in eighth grade are less likely to take higher-level math courses, placement in Algebra in eighth grade is recommended, along with curriculum and instructional supports included in this section. Additionally, schools should avoid tracking students by perceived readiness and instead create classrooms inclusive of all readiness levels.

While the historical debate on when students should take Algebra I has been a dichotomous argument focusing on either eighth or ninth grade, in light of analysis of international assessment results and examination of successful programs, withholding algebraic concepts and focusing on rote memorization of facts and processes in the early grades is an antiquated approach to preparing students for mathematics success. When students should take Algebra may not be the right question, which should instead shift to when do we introduce various algebraic concepts to students, starting with the early years of learning math?

Delivering a guaranteed and viable Algebra curriculum is not enough to ensure all students learn Algebra at high levels and are ready for advanced mathematics courses in high school and beyond. School systems must consider both academic content and social-emotional content when designing curriculum. For example, Intensified Algebra, which showed success in Florida, included mathematics and literacy content on equal footing with learning about 
the "malleability of intelligence, metacognition and goal setting, self-efficacy, and productive persistence-through explicit exercises embedded within content lessons as well as through the routines woven throughout the course" (Tidd et al., 2018, p. 99). Mathematics curriculum should be reviewed through both a lens of rigor and social-emotional elements. When students are provided with challenging curriculum built around prioritized standards addressing the big ideas of mathematical thinking, the opportunity exists to also build in more time to allow for inquiry, high-level discourse, and problem-solving. These components cannot be left to chance; they must be explicitly stated in the required curriculum. Perhaps most importantly, students should not have to wait until eighth or ninth grade to be exposed to algebraic concepts. In alignment with NCTM (2014) recommendations, abstract and algebraic concepts should be embedded throughout mathematics courses at the elementary and early middle-school level in order to build problem-solving skills. At the secondary level, eliminating what many call the "geometry sandwich" and providing students with integrated math courses, which include concepts from typically discreet courses of algebra, geometry, statistics, and data science is more in line with curriculum from the nations who do well on international assessments, such as PISA (OECD 2018b).

\section{Student Factors}

The results of this study indicated a significant correlation between students' academic self-concept and grades, which is also supported by previous research (Burnett et al., 1999; Liem et al., 2015; Marsh \& Martin, 2011). In light of these findings, it is imperative for teachers to understand the construct of academic self-concept and how it differs from selfesteem. Simply praising students for work and effort is not enough to positively impact academic selfconcept leading to higher achievement and mastery of course content. Instead, school administrators can support student achievement by ensuring that teachers understand and apply actionable feedback, use positive responses to students, and design instruction that allows for student questioning, inquiry, problemsolving, and relevant connections. Teacher observations should focus on the effective use of these strategies.

To help students build non-cognitive skills, such as problem-solving and perseverance, students should be given relevant problems to solve and taught that struggle is part of the learning process. Helping students to develop an understanding of how their brains learn has the potential to mitigate effects of the Big Fish, Little Pond Theory (Marsh, 1990), as students may look less to their peers to determine their own level of competence, and rely more on their own understanding of how they learn.

Although data in this study indicated no relationship between students' academic self-concept in mathematics and neither teachers' beliefs about teaching math, nor teachers' instructional styles; these results may have been the result of a misalignment between teachers' beliefs and their instructional styles, or the minimal data related to the students who received the instruction most aligned with constructivist teaching. Based on international testing data and the push for more interactive, studentcentered approaches to education, the researcher recommends schools move to a more constructivist 
approach to instruction, as a means for strengthening students' academic self-concept.

\section{Instructional Factors}

The teachers in this study indicated they valued the use of diverse strategies for problem-solving and the opportunity for students to investigate mathematical concepts; however, the instruction observed by the researcher included little, if any, opportunity for students to apply reasoning and problem-solving skills. Instead, the instruction was teacher-centered, and followed what can be considered a more traditional approach, with the teacher showing students how to solve a problem, giving students time to practice the technique, and then asking questions of students to check for understanding. In China, which consistently ranks high in mathematics (OECD, 2018a), successful teachers pointed to the value of time to collaborate and reflect on their instructional practices (Pepin et al., 2017). In light of this, the researcher recommends the study site consider professional development for teachers that emphasizes constructivist approaches to teaching math, and provides teachers with time and practice around how to effectively collaborate. To improve the academic achievement of students in Algebra, focusing on how teachers teach is imperative.

\section{Teacher Factors}

Assuring the quality of teacher-made assessments by helping teachers understand and apply concepts of high-quality assessment design, validity, and reliability measures would increase the likelihood of assessments aligned with grade-level standards, which would require assessments to focus on conceptual understanding over rote application of algebraic rules. Additionally, such assessments would allow for teachers to better understand the curriculum and design instruction that supports the kind of thinking required for students to demonstrate mastery.

\section{Leadership}

This study established a positive relationship between student self-concept in mathematics and mathematics achievement. School administrators can support student achievement by ensuring that teachers understand and apply actionable feedback, use positive responses to students, and design instruction that allows for student questioning, inquiry, problemsolving, and relevant connections.

\section{Practice}

When considering the hiring of mathematics teachers, a mixture of subject matter understanding and an ability to build and nurture the student's intrinsic selfvalue could be helpful qualities in new hires.

\section{Research}

While we educators tend to examine student selfconcept, teacher beliefs, instructional styles, and overall achievement in all areas of learning, we could benefit from increased study of these characteristics with emphasis on their specific effects on mathematics achievement. This study also established an observable, small, inverse relationship was found between unproductive teacher beliefs and students' self-concept in mathematics. This item warrants further exploration; especially since it indicates unproductive beliefs may strengthen self-concept.

\section{Policy}

An on-going examination of the placement of supporting skills within the continuum of mathematics study is warranted. For example, problem-solving 
skills support algebraic understanding; therefore, skills for problem-solving should be introduced early in a child's study curriculum. Early support of skills that contribute to the learning of higher-level mathematics, well-established early in a child's curriculum could advance the deeper understanding we hope our students develop at the end of high school and/or college.

\section{Summary}

Just as teachers need to be knowledgeable about assessment design principles, results of this study also indicate a need for educators to understand the construct of academic self-concept. Figure 1 provides a nice visual.

\section{Figure 1}

\section{Influential Factors on Academic Self-Concept}

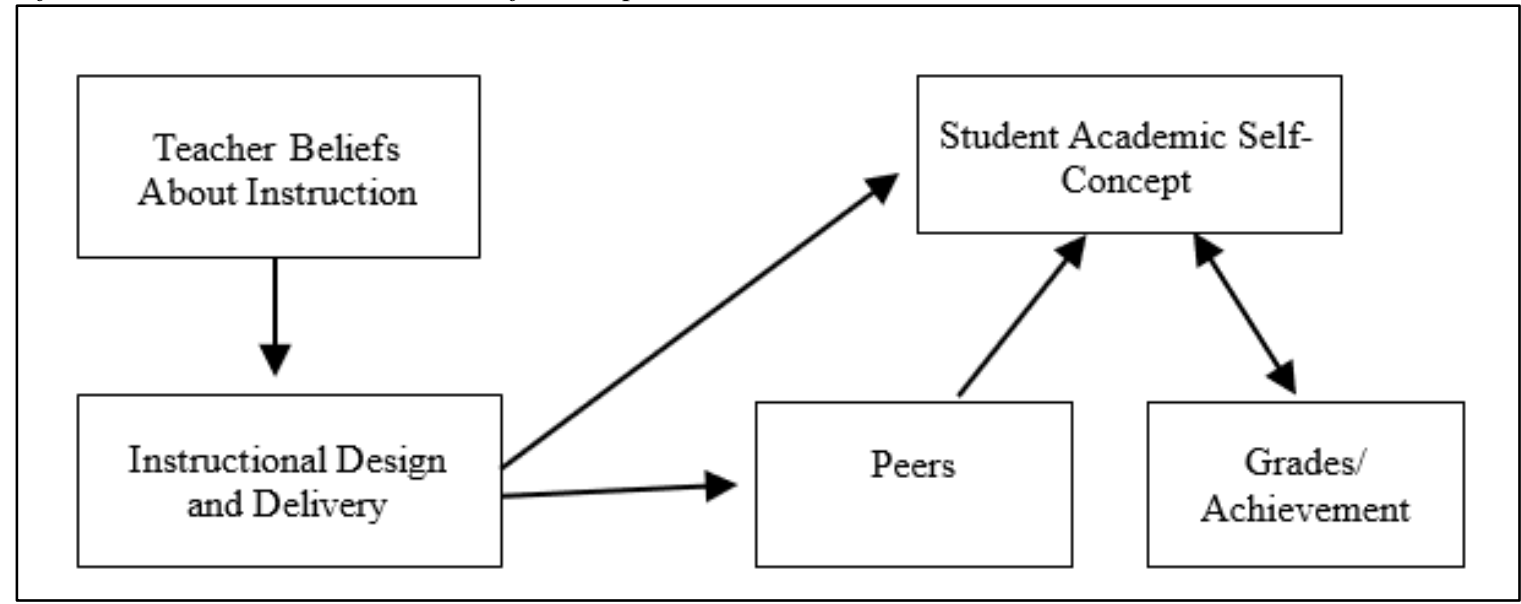

Teacher beliefs about instruction inform instructional design and delivery to students. This affects student self-concept and can influence how mathematics teachers. and their peers, approach instructional design and delivery. Student self-concept influences learning, which can effect change in achievement exhibited through interest in mathematics, improved achievement, and increased enrollment in higher-level mathematics.

\section{Future Research}

During the COVID-19 Pandemic, many of our k-12 students moved to online learning; both educators and students experienced adjustments to maintain successful learning, especially in the mathematics classroom. It is important that we maintain the peoplepart of learning. This study did not examine the potential relationships between self-concept, teacher beliefs, instructional styles, and overall achievement in the online setting. This situation provides a perfect scenario for continuing this examination in the newer setting. Problem solving and the self-concept within mathematics remains important; however, the educator is faced with more than the introduction of additional technology. Communicating step-by-step instructions and the reasoning of mathematics, as well as modeling the use of manipulatives is challenging. Development and support of the self-concept, within the mathematics setting will be challenging. 
Therefore, we emphasize the beliefs of teachers concerning their instructional strategies, the personal qualities that support our student's self-concepts, and the students' views of themselves as learners in a setting not normally a part of a mathematic class as variables to promote online success similar to that found in face-to-face classrooms.

\section{References}

American Psychological Association. (2020). Dictionary of Psychology [website]. https://dictionary.apa.org/hawthorne-effect

Boston, M., Bostic, J., Lesseig, K., \& Sherman, M. (2015, March). A comparison of mathematics classroom observation protocols. Mathematics Teacher Educator, 3(2), 154-175. http://www.jstor.org/stable/10.5951/mathteaceduc.3.2.0154

Burdman, P. (2018). The mathematics of opportunity: Rethinking the role of math in educational equity [Report]. Just Equations: https://justequations.org/

Burnett, P. C., Craven, R. G., \& Marsh, H, W. (1999). Enhancing students' self-concepts and related constructs: A critical longitudinal analysis capitalising on and combining promising enhancement techniques for educational settings. In AARE NZARE Conference 1999. Australia, Victoria, Melbourne. http://www.aare.edu.au/99pap/bur99425.htm

Cirino, P., Toler, T. D., \& Fuchs, L. S. (2018, May 29). Longitudinal algebra prediction for early versus later takers. The Journal of Educational Research, 112(2), 179-191. http://dx.doi.org/doi.org/10.1080/00220671.2018.1486279

Classroom Observation Project. (2018). [website]. https://serc.carleton.edu/NAGTWorkshops/certop/calculation.html

Clotfelter, C. T., Ladd, H. F., \& Vigdor, J. L. (2015, January 1). The aftermath of accelerating algebra: Evidence from district policy initiatives. Journal of Human Resources, 50, 159-188. http://dx.doi.org/10.3368/jhr.50.1.159

Cortez, K., Goodman, J., \& Nomi, T. (2013). Doubling up: Intensive math instruction and educational attainment. Paper presented at the SREE Spring Conference, Washington D.C. https://www.sree.org/conferences/2013s/

Fisher, D., \& Frey, N. (2013, February 5). Implementing RTI in high school: A case study. Journal of Learning Disabilities, 46(2), 99-114. http://dx.doi.org/10.1177/0022219411407923

Fraenkel, J. R., Wallen, N. E., \& Hyun, H. H. (2018). How to design and evaluate research in education (10th ed.). McGraw Hill.

Laerd (2018). Statistics [website]. https://statistics.laerd.com/statistical-guides/pearson-correlation-coefficientstatistical-guide.php

Liem, G. A., McInerney, D. M., \& Yeung, A. S. (2015). Academic self-concepts in ability streams: Considering domain specificity and same-stream peers. The Journal of Experimental Education, 83(1), 83-109. http://dx.doi.org/10.1080/10.1080/00220973.2013.876227 
Loveless, T. (2013). The algebra imperative: Assessing algebra in a national and international context. Brookings Institution Center on Education Policy.

Marsh, H. (1990). The structure of academic self-concept: The March/Shavelson model. Journal of Educational Psychology, 82(4), 623-636. http://www.grajfoner.com/Clanki/Marsh1990JoEP\%20Academic\%20Self\%20Concept.pdf\%20\%20

Marsh, H., \& Martin, A. J. (2011). Academic self-concept and academic achievement: Relations and causal ordering. British Journal of Educational Psychology, 81, 59-77. http://dx.doi.org/10.1348/000709910X503501

McEachin, A., Domina, T., \& Penner, A. (2017). Understanding the effects of middle school algebra: A regression discontinuity approach. Rand Corporation: https://www.rand.org/pubs/working_papers/WR1209.html

Missouri Department of Elementary and Secondary Education. (n.d.). [website]. https://apps.dese.mo.gov/MCDS/home.aspx

Mullis, I. V., Martin, M. O., Foy, P., \& Hooper, M. (2016). TIMSS 2015 International results in mathematics grade 8. TIMSS and PIRLS: http://timss2015.org/wp-content/uploads/filebase/full\%20pdfs/T15-InternationalResults-in-Mathematics-Grade-8.pdf

National Council of Teachers of Mathematics. (n.d.). [website]. https://www.nctm.org/Standards-andPositions/Principles-and-Standards/Principles,-Standards,-and-Expectations/

National Council of Teachers of Mathematics. (2014). Principles to actions: Ensuring mathematical success for all. National Council of Teachers of Mathematics.

Niepel, C., Brunner, M., \& Preckel, F. (2014, November). The longitudinal interplay of students' academic selfconcepts and achievements within and across domains: Replacing and extending the reciprocal internal/external frame of reference model. Journal of Educational Psychology, 106(4), 1170-1191. http://dx.doi.org/10.1037/a0036307

Office of Economic and Cooperative Development. (2018a). PISA 2015: Results in focus [brochure]. http://www.oecd.org/pisa/pisa-2015-results-in-focus.pdf

Office of Economic and Cooperative Development. (2018b). [website]. https://www.oecd.org/pisa/

Pena, K. L., Mujica, A. D., Navarrete, C. B., \& Perez-Villalobos, M. V. (2015). Construction and psychometric characteristics of the self-concept scale of interaction in the classroom. Psicothema, 27(2), 151-158. http://dx.doi.org/doi: 10.7334/psicothema2014.224

Pepin, B., Xu, B., Trouche, L., \& Wang, C. (2017). Developing a deeper understanding of mathematics teaching expertise: An examination of three Chinese mathematics teachers' resource systems as windows into their work and expertise. Educational Studies in Mathematics, 94, 257-274. https://doi.org/10.1007/s10649016-9727-2

Piburn, M., \& Sawada, D. (n.d.). Reformed teacher observation protocol (RTOP): Reference manual. ASU Modeling Instruction \& MNS Degree Programs: http://modeling.asu.edu/ 
Sawada, D., Piburn, M. D., Judson, E., \& Falconer, K. (2002). Measuring reform practices in science and mathematics classrooms: The reformed teaching observation protocol. School Science and Mathematics, 102(6), 245-253. http://dx.doi.org/10.1111/j.1949-8594.2002.tb17883.x

Stein, M. K., Kaufman, J. H., Sherman, M., \& Hillen, A. F. (2011). Algebra: A challenge at the crossroads of policy and practice. Review of Educational Research, 81(4), 453-492. http://dx.doi.org/10.3102/0034654311423025

The Nation's Report Card. (2016). [website]. https://www.nationsreportcard.gov/reading_math_2017_highlights/

Tidd, S. T., Stoelinga, T. M. Bush-Richards, A. M.,De Sena, D. L., \& Dwyer, T. J. (2018). An intensification approach to double-block algebra: A pilot implementation of intensified algebra in a large urban school district. Journal of Educational Research, 111(1), 95-107. ERIC - EJ1161560. https://doi.org/10.1080/00220671.2016.1209454

\section{Corresponding Author Contact Information:}

Author name: Sherrie Wisdom, EdD

Department: Educational Leadership

Faculty: College of Education \& Human Services

University, Country: Lindenwood University, United States

Email: swisdom@lindenwood.edu

Please Cite: Kulpa, S., \& Wisdom, S. (2021). An Investigation of Success Factors in a High School Algebra Intervention Program. Journal of Research in Science, Mathematics and Technology Education, 4(3), 205-224. DOI: https://doi.org/10.31756/jrsmte.433

Copyright: ( $) 2021$ JRSMTE. This is an open-access article distributed under the terms of the Creative Commons Attribution License, which permits unrestricted use, distribution, and reproduction in any medium, provided the original author and source are credited. 